Di rect effect of cadmum on ci trate upt ake by i sol at ed $r$ at renal br ush bor der menbr ane vesi cl es

\begin{tabular}{|l|l|}
\hline 著者 & $\begin{array}{l}\text { SATO Kazuhi ro, KUSAKA Yuki nor i , OKADA } \\
\text { Keni chi r o }\end{array}$ \\
\hline $\begin{array}{l}\text { j our nal or } \\
\text { publ i cat i on t i t l e }\end{array}$ & Toxi col ogy Let t er s \\
\hline vol une & 80 \\
\hline page $r$ ange & $161-165$ \\
\hline year & $1995-07$ \\
\hline URL & ht t p: //hdl . handl e. net /10098/5221 \\
\hline
\end{tabular}




\title{
Direct effect of cadmium on citrate uptake by isolated rat renal brush border membrane vesicles
}

\author{
Kazuhiro Sato* ${ }^{\text {a }}$, Yukinori Kusaka ${ }^{a}$, Kenichiro Okada ${ }^{b}$ \\ ${ }^{a}$ Department of Environmental Health, Fukui Medical School, 23 Shimoaizuki, Matsuoka-cho. Fukui 910-11, Japan

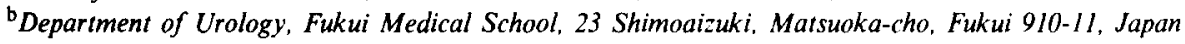

Received 8 April 1994; revision received 16 April 1995: accepted 20 April 1995

\begin{abstract}
High incidence of multiple kidney stone formation has been observed among workers exposed to cadmium (Cd). Citrate is known to be a protective factor against renal stone formation. To study the direct effect of cadmium on citrate uptake by the renal brush border membrane, we exposed isolated rat renal brush border membrane vesicles (BBMV) to cadmium and determined their citrate uptake characteristics. BBMV were prepared by the divalent cation precipitation method. Citrate uptake was measured by the Millipore rapid membrane filtration technique. Preincubation of BBMV with 2 and $10 \mathrm{mM} \mathrm{CdCl}$ for 1 min significantly inhibited citrate uptake compared with that of BBMV without $\mathrm{Cd}$. Analysis of the time course of citrate uptake during 30 -min preincubation of BBMV with $0.5 \mathrm{mM} \mathrm{Cd}$ also revealed significant reduction of the uptake compared with that of the control BBMV without preincubation. These findings indicate that preincubation of BBMV with cadmium results in time-dependent and concentration-dependent inhibition of citrate uptake.
\end{abstract}

Keywords: Cadmium; Renal stone; Citrate; Brush border membrane vesicle

\section{Introduction}

The incidence of urolithiasis in Japan, like that in other developed countries, has been steadily increasing since the Second World War [1], although the etiology of this condition is not completely understood. Occupational exposure to cadmium is associated with renal damage, particularly with proximal renal tubular dysfunction [2,3]. Chronic exposure to cadmium produces a renal tubular

\footnotetext{
* Corresponding author.
}

syndrome which includes aminoaciduria, proteinuria and hypercalciuria [4]. Some epidemiological studies have revealed that workers exposed to cadmium have a high incidence of renal stones [2]. Cadmium inhibits the Na-D-glucose [5], Ialanine [6] and L-glutamate [7] co-transport system in the rat renal brush border membrane. On the other hand, citrate is a well known inhibitor of the formation of calcium-containing renal stones, and has been shown to reduce the saturation of stone-forming calcium salts by forming a soluble complex with calcium [8]. The mechanism by 
which cadmium affects the Na-citrate co-transport system, however, has not been clarified.

In the present study, we exposed rat renal brush border membrane vesicles (BBMV) to cadmium and investigated the direct effect of this exposure on their citrate uptake. The results presented here suggest that cadmium might inhibit the Na-citrate co-transport system in renal brush border membranes.

\section{Materials and methods}

\subsection{Materials}

${ }^{14} \mathrm{C}$-Citrate (spec. act. $50 \mathrm{mCi} / \mathrm{m} \mathrm{mol}$ ) was obtained from the New England Nuclear Corp. (Boston, MA). All other chemicals were of reagent grade and purchased from commercial sources.

\subsection{Animals}

Experiments were performed using isolated brush border membranes obtained from male Wistar rats (CLEA, Japan, Inc.) weighing 290-340 g. They were fed a control diet and tap water ad libitum in a temperature and humidity-controlled room under a 12-h light-dark cycle.

\subsection{Brush border membrane isolation}

Each brush border membrane specimen was prepared from the cortex of both kidneys of a single rat by a modification of the $\mathrm{MgCl}_{2}$-precipitation technique [9]. During preparation, all materials were maintained at $4^{\circ} \mathrm{C}$. Briefly, each rat was anesthetized with chloral hydrate $(360 \mathrm{mg} / \mathrm{kg}$ body wt.) administered intraperitoneally. The renal cortices were removed and placed in isolation buffer consisting of (in mM) 50 mannitol and 2 Tris-(hydroxymethyl)-aminomethane (Tris) $/ \mathrm{HCl}$ at $\mathrm{pH}$ 7.0. They werc homogenized in a glass Teflon homogenizer (Iuchi Co. Ltd., Japan) and a polytron homogenizer. A concentration of $\mathrm{MgCl}_{2}$ (1 M) was added to the resultant homogenate to give a final concentration of $10 \mathrm{mM}$. This mixture was stirred for $20 \mathrm{~min}$ in a cold room and then centrifuged for $15 \mathrm{~min}$ at $3000 \times \mathrm{g}$. The supernatant was collected and centrifuged for $20 \mathrm{~min}$ at 43000 $x g$. The pellet containing the brush border membrane vesicles was resuspended in isolation buffer and centrifuged for $15 \mathrm{~min}$ at $3000 \times g$. The super- natant was centrifuged for $20 \mathrm{~min}$ at $43000 \times \mathrm{g}$. The pellet containing the purified brush border membrane vesicles (BBMV) was resuspended in (in $\mathrm{mM}$ ) 260 mannitol and $20 \mathrm{~N}^{2}$-hydroxyethylpiperazine- $N^{\prime}$ 2-ethanesulfonic acid (Hepes)/Tris, $\mathrm{pH} 7.0$, at a final concentration of about $10 \mathrm{mg}$ protein $/ \mathrm{ml}$.

\subsection{Enzyme assays}

The purity of the membrane preparations was assessed by evaluation of the enrichment of alkaline phosphatase (ALP) [10] and leucine aminopeptidase (LAP) [11] in the final preparation as compared with that of original homogenate.

\subsection{Protein determination}

Protein determination was conducted by the method of Lowry et al. [12] using crystalline bovine serum albumin as the standard.

\subsection{Uptake studies}

Citrate uptake is sodium dependent and electrogenic such that positive charge is transported [13]. The uptake of citrate by the BBMV was determined by the Millipore rapid membrane filtration technique [14-17]. In time course experiments, membrane vesicles $(10 \mu \mathrm{l})$ were incubated at $30^{\circ} \mathrm{C}$ with $40 \mu \mathrm{l}$ of uptake solution consisting of (in $\mathrm{mM}$ ) $0.1{ }^{14} \mathrm{C}$-citrate, $130 \mathrm{NaCl}$ or $\mathrm{KCl}, 20$ Hepes/Tris, with or without $0.5 \mathrm{CdCl}_{2}, \mathrm{pH} 7.0$. At appropriate intervals, the uptake was terminated by the addition of $4 \mathrm{ml}$ of ice-cold solution consisting of (in $\mathrm{mM}$ ) $130 \mathrm{NaCl}$ or $\mathrm{KCl}, 20$ Hepes/ Tris, $\mathrm{pH}$ 7.0. The solution was then rapidly filtered through a Millipore filter (DAWP02500; pore size, $0.65 \mu \mathrm{m}$ ) and washed twice with $4 \mathrm{ml}$ of ice-cold stop solution under vacuum suction. For the experiment in which BBMV were preincubated with $\mathrm{CdCl}_{2}$, membrane vesicles $(10 \mu \mathrm{l})$ were preincubated at $30^{\circ} \mathrm{C}$ with $10 \mu \mathrm{l}$ of preincubation solution consisting of (in $\mathrm{mM}$ ) 260 mannitol, 20 Hepes/Tris, pH 7.0, with or without $\mathrm{CdCl}_{2}$. Citrate uptake was initiated by the addition of $40 \mu \mathrm{l}$ of uptake solution consisting of (in $\mathrm{mM}$ ) $0.1{ }^{14} \mathrm{C}$ citrate, $130 \mathrm{NaCl}, 20 \mathrm{Hepes} / \mathrm{Tris}, \mathrm{pH}$ 7.0. After thirty seconds, uptake was terminated by the addition of $4 \mathrm{ml}$ of ice-cold solution consisting of (in mM) $130 \mathrm{NaCl}, 20$ Hepes/Tris, pH 7.0. The solu- 
tion was then rapidly filtered through a Millipore filter (DAWP02500: pore size $0.65 \mu \mathrm{m}$ ) and washed twice with $4 \mathrm{ml}$ of ice-cold stop solution under vacuum suction. Background uptake was determined similarly by adding $4 \mathrm{ml}$ ice-cold stop solution to membrane vesicles $(10 \mu \mathrm{l})$ before adding 40 $\mu l$ of uptake solution at $0^{\circ} \mathrm{C}$. Non-specific binding was always $<0.5 \%$ of the total counts in the uptake solution. Radioactivity associated with the filters was measured with a liquid scintillation counter (LSC-3500, Aloka). All uptake measurements were performed at $30^{\circ} \mathrm{C}$ in triplicate, and uptake was calculated on the basis of specific activity measured in each experiment. The value of non-specific binding was subtracted from the experimental value and the vesicular uptake was expressed as picomoles ${ }^{14} \mathrm{C}$-citrate per $\mathrm{mg}$ protein. Student's $t$-test was used to analyze differences among the groups. Significance was accepted at $P$ $<0.05$.

\section{Results}

The purity of the BBMV preparations was assayed by determining the BBM-specific marker enzymes ALP and LAP. The specific activities of the two enzymes in the BBM fraction were enriched by about 10 -fold over those in the original homogenate.

\subsection{Effect of cadmium in the uptake solution on} time course of citrate uptake by $B B M V$

When BBMV were prepared in $\mathrm{NaCl}$-free medium and incubated in $130 \mathrm{mM} \mathrm{NaCl}$-containing buffer, the uptake of citrate showed a characteristic 'overshoot' phenomenon during the first 2 min and reached equilibrium after $120 \mathrm{~min}$ (Fig. 1). The overshoot indicates an intravesicular accumulation of citrate above the equilibrium concentration and occurs because of the persistence of a $\mathrm{Na}^{+}$gradient when the intravesicular citrate has already reached the concentration in the incubation medium [18]. But there was no significant difference between the uptake solution with $0.5 \mathrm{mM}$ $\mathrm{CdCl}_{2}$ and the uptake solution without $\mathrm{CdCl}_{2}$. When the $\mathrm{Na}^{+}$gradient was replaced by a $\mathrm{K}^{+}$gradient, the initial uptake of citrate was very low and the overshoot did not occur (Fig. 1).

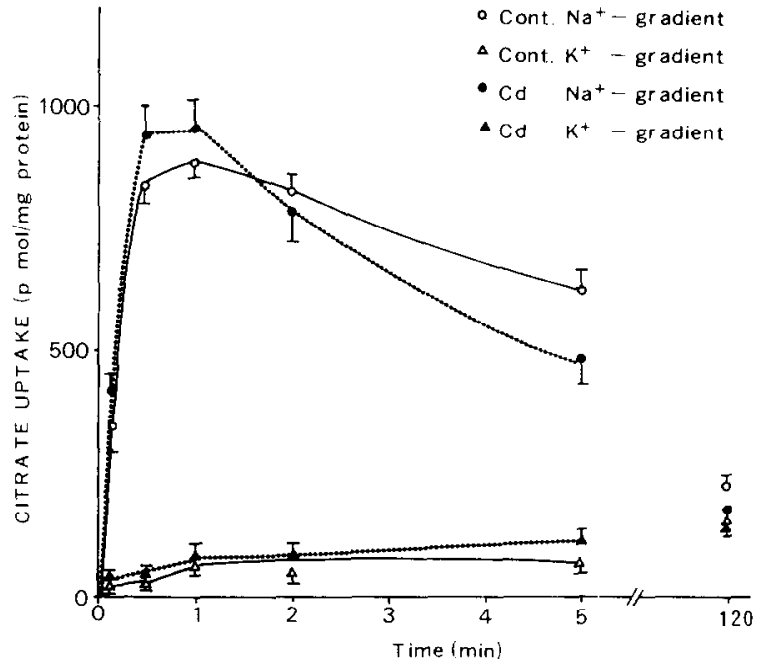

Fig. 1. Time course of $\mathrm{Na}^{+}$-dependent and independent citrate uptake in rat renal brush border membrane vesicles. To vesicles consisting of (in mM) 260 mannitol, 20 Hepes/Tris, pH 7.0, uptake solution consisting of (in $\mathrm{mM}$ ) $130 \mathrm{NaCl}(0,0)$ or $\mathrm{KCl}(\Delta, \Delta), 20 \mathrm{Hepes} / \mathrm{Tris}$, with $(\boldsymbol{\theta}, \boldsymbol{\Delta})$ or without $(0, \Delta) 0.5$ $\mathrm{CdCl}_{2}, \mathrm{pH} 7.0$, was added. Values are means \pm S.E.

\subsection{Effect of cadmium and cadmium concentration} on citrate uptake by $B B M V$

The effect of preincubation of BBMV with $0-10$ $\mathrm{mM} \mathrm{Cd}$ for $1 \mathrm{~min}$ at $30^{\circ} \mathrm{C}$ is illustrated in Fig. 2 .

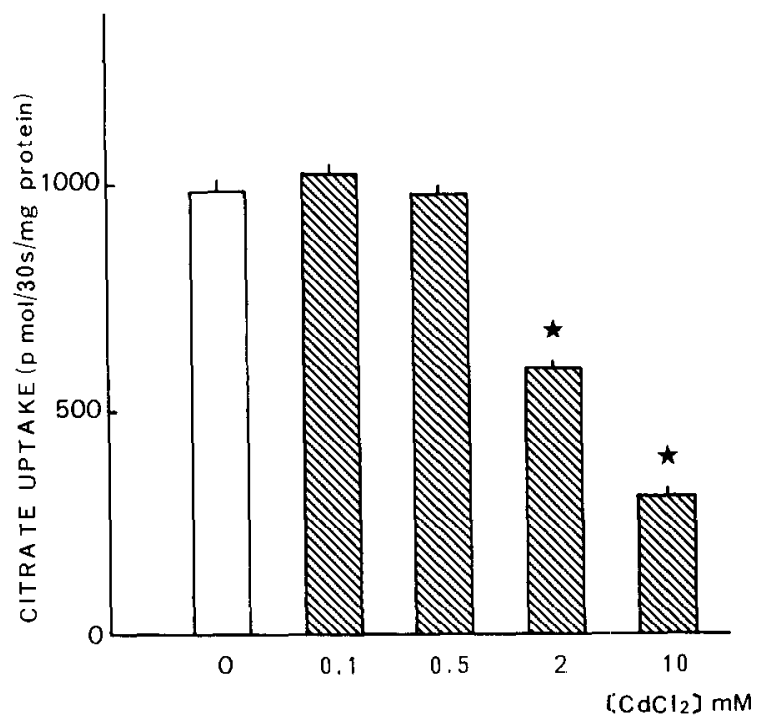

Fig. 2. Effect of preincubation for $1 \mathrm{~min}\left(30^{\circ} \mathrm{C}\right)$ with cadmium at various concentrations on citrate uptake by brush border membrane vesicles. Values are means \pm S.E. ${ }^{*} P<0.002$ vs. uptake at $0 \mathrm{mM}$. 


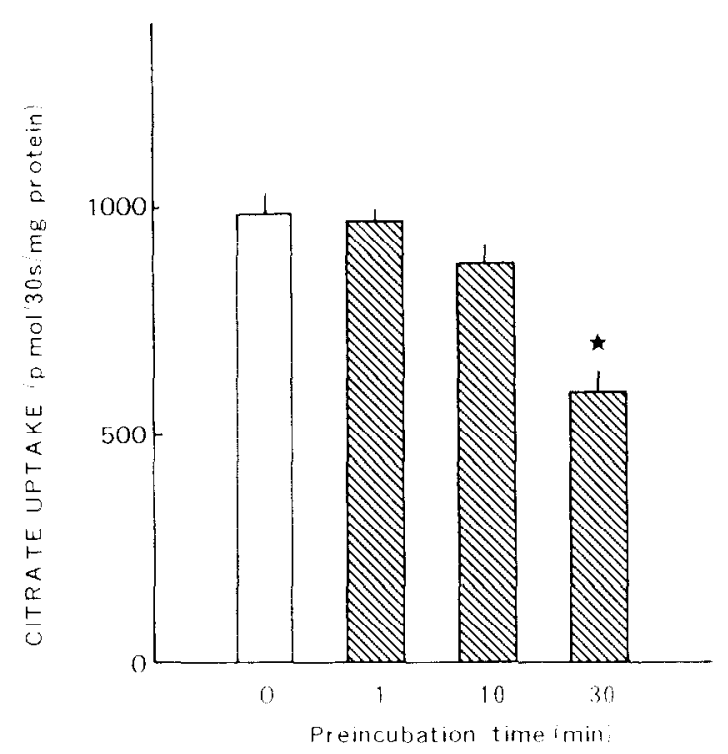

Fig. 3. Effect of cadmium on citrate uptake by brush border membrane vesicles with respect to pre-incubation time. Values are means \pm S.E. ${ }^{*} P<0.02$ vs. 0 min.

Preincubation with 2 and $10 \mathrm{mM}$ Cd significantly inhibited the citrate uptake compared with that without preincubation. These findings indicate that preincubation with $\mathrm{Cd}$ resulted in concentration-dependent inhibition of citrate uptake by BBMV.

\subsection{Effect of cadmium on citrate uptake by $B B M V$ with respect to preincubation time}

Fig. 3 shows the time course of inhibition of citrate uptake after preincubation with $0.5 \mathrm{mM}$ $\mathrm{Cd}$. Following preincubation for 1 and $10 \mathrm{~min}$, citrate uptake by BBMV was decreased, but not significantly so. Following 30 -min preincubation, significant inhibition of the citrate uptake compared with that of the control without preincubation was observed. These findings indicate that $\mathrm{Cd}$ preincubation resulted in time- and concentrationdependent inhibition of citrate uptake by BBMV.

\section{Discussion}

The kidney is a major target organ of cadmium in animals and humans [4]. Cadmium impairs various components of the transport system in the proximal tubules [5-7]. Proteinuria is often an early sign of cadmium intoxication, and changes in reabsorption of calcium also occur early in the course, leading to hypercalciuria. In cadmium intoxication, hypercalciuria without proteinuria is sometimes observed [2]. The results of a previous epidemiological study revealed that the prevalence of renal stones in non-proteinuric men was higher than that in proteinuric men, suggesting that more developed tubular dysfunction was associated with lower risk of development of kidney stones [2]. However, the mechanism by which cadmium affects the transtubular transport process in the kidney is not known.

Na-dependent D-glucose uptake by BBMV is inhibited by $\mathrm{Cd}$ because $\mathrm{Cd}$ binds the external site of BBMV and reacts with sites on the Na-Dglucose co-transporter [5]. In the time course experiment, there was no significant difference between the uptake solution with and without 0.5 $\mathrm{mM} \mathrm{CdCl}$. However, preincubation of BBMV with cadmium resulted in time- and concentrationdependent inhibition of the citrate uptake by the BBMV. So, citrate is thought to have been taken up by the BBMV before Cd binding could occur.

Workers exposed to cadmium for a long period or at high dose, therefore, might have increased urinary citrate excretion, which prevents renal stones. In contrast, short-term or low-dose exposure to cadmium may cause hypercalciuria but may not increase urinary citrate excretion, which may cause a predisposition to renal stones. Urinary citrate excretion is extremely sensitive to changes in the systemic acid-base balance [19] and in potassium balance [17]; excretion is increased in metabolic alkalosis and decreased in metabolic acidosis and potassium depletion, the latter of which is associated with renal intracellular acidosis [20]. Cadmium intoxication may lead to metabolic and respiratory acidosis [2]. The urinary citrate excretion in individuals with cadmium intoxication seems to be determined by the two factors of acidosis and impairment of the citrate transport system in the brush border membrane.

In conclusion, we infer from epidemiological studies that individuals with cadmium intoxication and hypercalciuria have a high risk of developing 
renal stones. Nevertheless, the findings of preincubation of rat BBMV with cadmium indicated that high direct exposure to cadmium impaired the citrate uptake by the BBMV and might reduce risk of development of renal stones. In vivo experiments (cadmium-intoxicated rats) are, thus, needed to study a possible mechanism for renal stones observed among Cd-exposed workers.

\section{References}

[1] Yoshida, O. and Okada, Y. (1990) Epidemiology of urolithiasis in Japan: a chronological and geographical study. Urol. Int. 45, 104-111.

[2] Friberg, L., Piscator, M., Nordberg G.F. and Kjellstrom, T. (1974) Cadmium in the Environment. 2nd edn. CRC Press, Cleveland, $\mathrm{OH}$, pp. 101-114

[3] Friberg, L. (1950) Health hazards in the manufacture of alkaline accumulators with special reference to chronic cadmium poisoning. Acta Med. Scand. Suppl. 240, 7-124.

[4] Bevan, C., Kinne-Saffran, E., Foulkes, E.C. and Kinne, R.K.H. (1989) Cadmium inhibition of L-alanine transport into renal brush membrane vesicles isolated from the winter flounder (Pseudopleuronectes americanus). Toxicol. Appl. Pharmacol. 101, 461-469.

[5] Bevan, C. and Foulkes, E.C. (1989) Interaction of cadmium with brush border membrane vesicles from the rat small intestine. Toxicology 54, 297-309.

[6] Kim, K.R., Lee, H.Y., Kim, C.K. and Park, Y.S. (1990) Alteration of renal amino acid transport system in cadmium-intoxicated rats. Toxicol. Appl. Pharmacol. 106, 102-111.

[7] Lee, H.Y., Kim, K.R., Woo, J. S., Kim, Y.K. and Park, Y.S. (1990) Transport of organic compounds in renal plasma membrane vesicles of cadmium intoxicated rats. Kidney Int. 37, 727-735.

[8] Nicar, M.J., Peterson, R. and Pak, C.Y.C. (1984) Usc of potassium citrate supplement during thiazide therapy of calcium nephrolithiasis. J. Urol. 131, 430-433.
[9] Booth, A.G. and Kenny, A.J. (1974) A rapid method for the preparation of microvilli from rabbit kidney. Biochem. J. 142, 575-581.

[10] Hansen, P.W. (1966) A simplification of Kind and King's method for determination of serum phosphatase. Scand. J. Clin. Lab. Invest. 18, 353-356.

[11] Goldberg, J.A. and Rutenberg, A.M (1958) The colorimetric determination of leucine aminopeptidase in urine and serum of normal subjects and patients with cancer and other diseases. Cancer 11, 283-291.

[12] Lowry, O.H., Rosebrough, N.J. Farr, A.L. and Randall, R.J. (1951) Protein measurement with the Folin phenol reagent. J. Biol. Chem. 193, 265-275.

[13] Hamm, L.L. (1990) Renal handling of citrate. Kidney Int. 38, 728-735.

[14] Wright, S.H., Kippen, I. and Wright, E.M. (1982) Stoichiometry of $\mathrm{Na}^{+}$-succinate cotransport in renal brush-border membranes. J. Biol. Chem. 257, 17731778.

[15] Jenkins, A.D., Dousa, T.P. and Smith, L.H. (1985) Transport of citrate across renel brush border membrane: effects of dietary acid and alkali loading. Am. J. Physiol. 249, F590-F595.

[16] Sato, K., Nishibuchi, S. and Okada, K. (1993) Effect of thiazide on urinary citrate excretion. Jpn. J. Nephrol. 35, 679-686 (in Japanese with English abstract).

[17] Sato, K., Nishibuchi, S. and Okada, K. (1993) Effect of high dose thiazide treatment and low-K diet on citrate uptake by rat renal brush border membrane vesicles (BBMV). Jpn. J. Nephrol. 35, 1115-1121 (in Japanese with English abstract).

[18] Lucke, H., Stange, G. and Murer, H. (1979) Sulphateion/sodium ion co-transport by brush-border membrane vesicles isolated from rat kidney cortex. Biochem. J. 182 , 223-229.

[19] Simpson, D.P. (1983) Citrate excretion: a window on renal metabolism. Am. J. Physiol. 244, F223-F234.

[20] Adam, W.P., Koretsky A.P. and Weiner, M.W. (1986) ${ }^{31} \mathrm{P}-\mathrm{NMR}$ in vivo measurement of renal intracelluar $\mathrm{pH}$ : effects of acidosis and $\mathrm{K}^{+}$depletion on rats. Am. J. Physiol. 251, F904-F910. 